\title{
Electrochemical transfer of cation between two electrolytes through a mineral junction
}

\author{
S.Seghir, C.Boulanger, S.Diliberto, J-M.Lecuire \\ Laboratoire d'Electrochimie des Matériaux (LEM/LCSM) \\ Université Paul Verlaine Metz, CNRS, 1 bd ARAGO, 57078 METZ Cedex 3 \\ sakina.seghir@univ-metz.fr \\ lecuire1@univ-metz.fr
}

\section{Introduction}

The industrial activity generates large amounts of liquid waste containing heavy metals. Processes used for treating this kind of materials are precipitation, solvent extraction or ion exchange. The limits of such treatments are due to their selectivity towards cations mixtures. A new original electrochemical way is purposed as an alternative of these techniques. This work deals with the extraction and the selective transfer of metal ions contained in liquid effluents or in lixiviats of industrial processes. This technique is based on the reversible redox reactions of insertion and deinsertion of cations in mineral host lattice matrices. The mineral matrix consist in a ternary molybdenum chalcogenides $\mathrm{M}_{\mathrm{x}} \mathrm{Mo}_{6} \mathrm{X}_{8}$ (where $\mathrm{M}=$ ternary metal cation and $\mathrm{X}=\mathrm{S}, \mathrm{Se}$ ) known as Chevrel phases discovered by Chevrel, Sergent and Prigent in $1971^{[1]}$. The reversible insertion/deinsertion reactions are easily realized by the oxidation/reduction electrochemical way when the ionic radius of the cation is less than 0,1 nm such as $\mathrm{Co}, \mathrm{Ni}, \mathrm{Mn}, \mathrm{Fe}, \mathrm{Zn}, \mathrm{Cu}$ and $\mathrm{Cd}^{[2,3]}$.

I. Principle of treatment

The ternary molybdenum chalcogenides have a rigid molybdenum chalcogen structure in which the cation enters in a three dimensional channels. The electronic sensitivity of the clusters and the high mobility of the ternary metal atom $(\mathrm{M}=$ small cation $){ }^{[4]}$ go together with an ionic transfer leading to redox reactions via electron/ion transfer process ${ }^{[5,6,7,8]}$. The process is based on the topotactic insertion/deinsertion reactions in Chevrel phases ${ }^{[9,10]}$ which concern the $\mathrm{Mo}_{6}$ cluster in $\mathrm{Mo}_{6} \mathrm{X}_{8}$ units (with $\mathrm{X}=\mathrm{S}, \mathrm{Se}$ ) according to the following relation:

$$
\mathrm{Mo}_{6} \mathrm{X}_{8 \downarrow}+\mathrm{xne}^{-}+\mathrm{xM}^{\mathrm{n}+} \underset{(2)}{\stackrel{(1)}{\gtrless}} \mathrm{M}_{\mathrm{x}} \mathrm{Mo}_{6} \mathrm{X}_{8 \downarrow}
$$

The electrochemical transfer junction (ETJ) (fig.1) consists of a $\mathrm{Mo}_{6} \mathrm{X}_{8}$ disc compacted which is a watertight mineral junction between two electrolytes compartments. In the global electrolysis of the two cells whole, two reactions occur:

- the insertion (1) of the cation $\mathrm{M}$ at the interface $\mathrm{M}_{\mathrm{x}} \mathrm{Mo}_{6} \mathrm{~S}_{8} /$ electrolyte 1;

- the reversible deinsertion (2) of the same cation $\mathrm{M}$ at the interface $\mathrm{M}_{\mathrm{x}} \mathrm{Mo}_{6} \mathrm{~S}_{8}$ /electrolyte 2 .

The principle of this process was involved in another exploitation of the redox system of insertion and deinsertion for the exchange of cations under electrochemical control, in the frame of recovery and valorization of effluents.

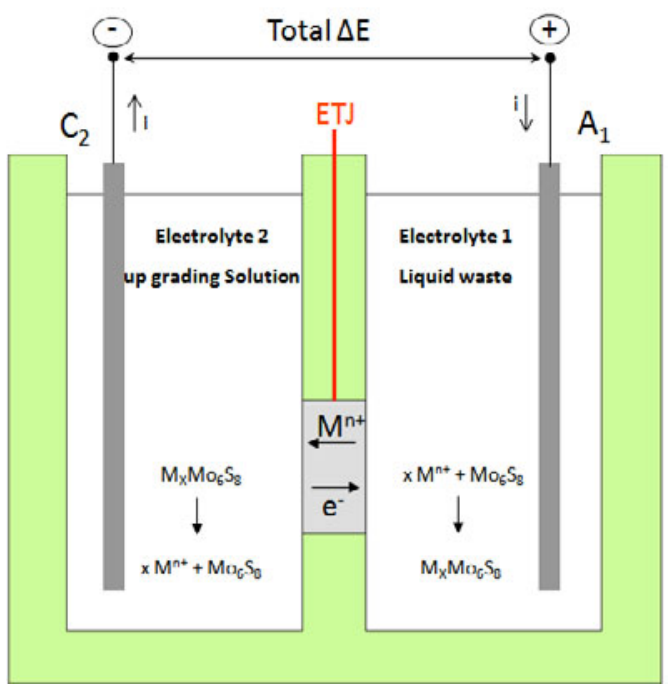

Fig 1. Principle of electrochemical transfer in a two cell process 


\section{Experimental details}

\section{Electrochemical Transfer Junction (ETJ)}

This disc is obtained by a technique of synthesis at high temperature. This ETJ consists of a $\mathrm{Mo}_{6} \mathrm{~S}_{8}$ or $\mathrm{Mo}_{6} \mathrm{Se}_{8}$ disc compacted by hot pressing. This method consists with a synthesis by reactive hot pressing, from mixture of powder of composition adapted for the stoichiometry of desired material ${ }^{111}$. The synthesis of ETJ by hot pressing is related to binary and ternary compounds such as:

- ternary $\mathrm{Cu}_{3} \mathrm{Mo}_{6} \mathrm{~S}_{8}$ (Tempeature of pressing : $1000^{\circ} \mathrm{C}$, Pressure applied: $30 \mathrm{MPa}$ )

$$
3 \mathrm{Cu}^{\circ}+4 \mathrm{MoS}_{2}+2 \mathrm{Mo}^{\circ} \rightarrow \mathrm{Cu}_{3} \mathrm{Mo}_{6} \mathrm{~S}_{8}
$$

- binary $\mathrm{Mo}_{6} \mathrm{Se}_{8}$ (Temperature of pressing: $1200^{\circ} \mathrm{C}$, Pressure applied: $30 \mathrm{MPa}$ )

$$
4 \mathrm{MoSe}_{2}+2 \mathrm{Mo}^{\circ} \rightarrow \mathrm{Mo}_{6} \mathrm{Se}_{8}
$$

In spite of the polycrystalline character of the $\mathrm{Mo}_{6} \mathrm{~S}_{8}$ or $\mathrm{Mo}_{6} \mathrm{Se}_{8}$ junction, we have obtained a disc (thickness $=4 \mathrm{~mm}$, diameter $=25 \mathrm{~mm}$ ) with a compactness rate about $98 \%$. Moreover it is necessary to carry out a compact interface in order to develop a good electronic conductivity and the best diffusion of the ions.

\section{Electrolysis cells}

All experiments were carried out in a laboratory built cell. It is made of PVC and constituted in two compartments of $100 \mathrm{~mL}$ :

- compartment 1 (liquid waste cation to be transferred = insertion from the ion)

- compartment 2 (electrolyte of beneficiation = deinsertion of ion)

The ETJ is placed between two compartments and an electronic contact allows us to control the potential (by a device of mechanical grip).

The system of insertion-deinsertion was studied in a global galvanostatic mode which is established between the anode $A_{1}$ (platinated titanium) of compartment 1 and the cathode $\mathrm{C}_{2}$ (stainless steel) of compartment 2 .

\section{Controls}

\subsection{Control of working interface potentials}

The follow-up of the potentials compared with the reference electrodes in the electrolytes 1 and 2 allow to control the electrochemical process developed in interfaces 1 and 2 of the ETJ during the cation transfer operation.

\subsection{Chemical control of transfer}

During the electrochemical transfer operation, the quantity of cation transferred was followed according to time and current density applied in compartment 2 in order to determine the cation transferred concentration. The samples assay were achieved by atomic absorption spectroscopy (AAS) leading to the determination of the transfer faradic yield and to the checking of the junction watertight.

\section{Results and Discussion}

\section{Cobalt ion}

Firstly, the aim of experiment was to check the extraction and the transfer of the cobalt cation chosen as ion test for a $\mathrm{Mo}_{6} \mathrm{~S}_{8}$ junction. To carry out this process, an electrolyte of cobalt sulphate $\mathrm{CoSO}_{4}(0,1 \mathrm{M})$ as source electrolyte in compartment 1 and a solution of sodium sulphate $\mathrm{Na}_{2} \mathrm{SO}_{4}(0,1 \mathrm{M})$ as beneficiation electrolyte in compartment 2 were used. The figure 
2 show results of cobalt quantities transferred according to the time of electrolysis and to the current density. Theses quantities are directly proportional to the time and the current densities. The results confirm the feasibility of a transfer process. In the case of cobalt, a transfer faradic yield about $100 \%$ was achieved for the range of applied current density. The transfer speeds are about $5.10^{-6} \mathrm{~mol} / \mathrm{h} / \mathrm{cm}^{2}$ for the $\mathrm{Mo}_{6} \mathrm{~S}_{8}$ junction. These speeds are directly related to the diffusion coefficient of cation in the mineral matrix. They depend on the diffusion coefficient $\left(4.10^{-6} \mathrm{~cm}^{2} / \mathrm{s}\right)$ for cobalt in the sample.

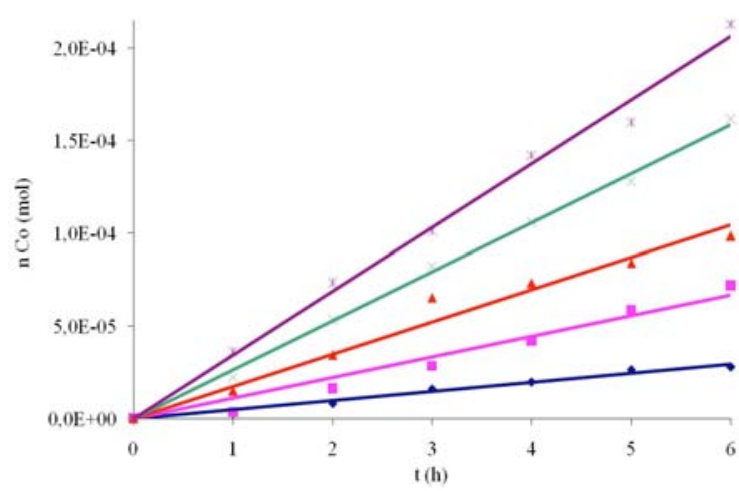

Fig 2. Follow-up of the quantity of cobalt transferred according to the time and the current density in compartment 2

The figure 3 represents, after the 6 hours of electrolysis operation, the transfer faradic yield and the potentials of interfaces $E_{1}$ and $E_{2}$ corresponding respectively to the insertion and deinsertion for the different current densities. The good performance of the process is provided until $1,5 \mathrm{~mA} / \mathrm{cm}^{2}$. Up to this value, the electrolysis only allows the transfer of cation and the insertion-deinsertion potentials $\left(\mathrm{E}_{1}\right.$ and $\left.\mathrm{E}_{2}\right)$ are in accordance with the position of the redox potential $\mathrm{Co}^{2+} / \mathrm{Mo}_{6} \mathrm{~S}_{8}(\mathrm{E}=-0,450 \mathrm{~V} / \mathrm{SCE})$. At higher current densities, the transfer faradic yields decrease and the potentials of interfaces change. This evolution is due to a new redox system which appears to assume the strong intensities. On the one hand, the potential of the interface of insertion $\mathrm{E}_{1}$ is decreasing because the reaction of the system $\mathrm{H}_{2} \mathrm{O} / \mathrm{H}_{2}$ water reduction occurs. Consequently, the electrochemical insertion yield of cobalt is decreasing. On the other hand, the deinsertion potential $\mathrm{E}_{2}$ is increasing whereas the transfer faradic yield of the cation is decreasing. At this potential, the oxidation of the molybdenum chalcogen structure takes place according to the reaction given by Boulanger ${ }^{[12]}$. This potential induces the degradation of the $\mathrm{Mo}_{6} \mathrm{~S}_{8}$ junction. It is necessary to adapt the current density, in order to avoid potentials higher than $0,4 \mathrm{~V} / \mathrm{SCE}$ and oxidation of host lattice for interface 2 of deinsertion. This limit concerns also the $\mathrm{Mo}_{6} \mathrm{Se}_{8}$ network and whatever the cation.

The development led for the ion $\mathrm{Co}^{2+}$ was extended to other metallic cations of metals. The transfer protocol was successfully tested on different cations ( $\mathrm{Ni}, \mathrm{Cd}, \mathrm{Cu}, \mathrm{Mn}, \mathrm{Zn}$ ) directly engaged in the industry of batteries.

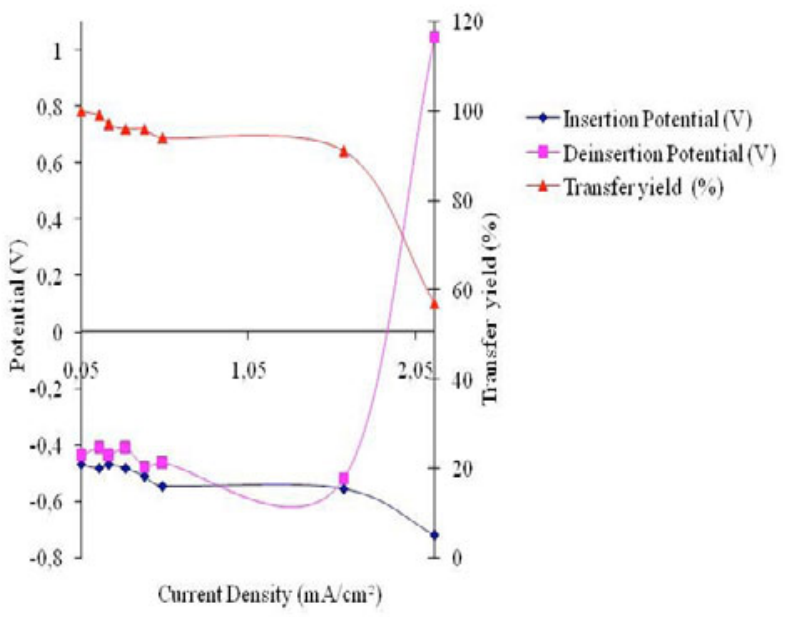

Fig 3. Transfer yield of cobalt and potentials according to the current densities applied.

\section{Mixtures}

The metals ions solutions treatment is also examined by the selectivity of the electrolysis protocols. The insertion of a cation $\mathrm{M}$ in a mineral matrix ( $\mathrm{S}$ or Se) takes place in a range of specific potential depending to the nature of the cation, the matrix and chemical parameters of the electrolyte to be treated. It is the same for the deinsertion. For a selectivity of the insertion between two cations $\mathrm{M}$ and $\mathrm{M}$ ', the applied current density must impose a work potential located in the insertion range of the cation $\mathrm{M}$ without reaching in the potential range where 
the additional insertion of the cation $M^{\prime}$ occurs. The experimental study of the selective transfer was undertaken for mixtures of cations, and the results are represented in table I. Preliminary tests were undertaken on ETJ of different natures such as $\mathrm{Mo}_{6} \mathrm{~S}_{8}$ and $\mathrm{Mo}_{6} \mathrm{Se}_{8}$ from various mixtures of two equimolar cations $(0,1 \mathrm{M})$. The selectivity results in the ratio of transferred cations $\mathrm{M}_{\mathrm{t}}^{\mathrm{n}+}$ in compartment $2: \mathrm{M}^{\mathrm{n}+}{ }_{\mathrm{t}} / \Sigma \mathrm{M}_{\mathrm{i}}^{\mathrm{n}+}$

- $\mathrm{Co}_{\mathrm{t}} /\left(\mathrm{Co}_{\mathrm{t}}+\mathrm{Ni}_{\mathrm{t}}\right)$ for the mixture $\mathrm{Co}^{2+} / \mathrm{Ni}^{2+}$

- $\quad \mathrm{Cd}_{\mathrm{t}} /\left(\mathrm{Cd}_{\mathrm{t}}+\mathrm{Ni}_{\mathrm{t}}\right)$ for the mixture $\mathrm{Cd}^{2+} / \mathrm{Ni}^{2+}$

The possibility to use an electrochemical transfer junction (ETJ) for the selective extraction of a cation from an industrial effluent was demonstrated. For the case of a $\mathrm{Cd} / \mathrm{Ni}$ mixture, a selectivity rate about $70 \%$ was obtained with a $\mathrm{Mo}_{6} \mathrm{~S}_{8}$ ETJ. This selectivity becomes practically to $100 \%$ for a $\mathrm{Mo}_{6} \mathrm{Se}_{8}$ ETJ. The nature of the ETJ is very important for the selectivity.

\begin{tabular}{|c|c|c|c|c||c|c|c|}
\cline { 2 - 7 } \multicolumn{1}{c|}{} & \multicolumn{4}{c|}{ Mo $_{\mathbf{8}} \mathbf{S}_{\mathbf{8}}$} & \multicolumn{3}{c|}{$\mathbf{M o}_{\mathbf{6}} \mathbf{S e}_{\mathbf{8}}$} \\
\hline $\begin{array}{c}\text { Source } \\
\text { solutions } \\
(0,1 \mathrm{M})\end{array}$ & $\mathrm{Co} / \mathrm{Ni}$ & $\mathrm{Co} / \mathrm{Cu}$ & $\mathrm{Cd} / \mathrm{Zn}$ & $\mathrm{Cd} / \mathrm{Ni}$ & $\mathrm{Cd} / \mathrm{Ni}$ & $\mathrm{Cd} / \mathrm{Zn}$ & $\mathrm{Mn} / \mathrm{Zn}$ \\
\hline $\begin{array}{c}\text { Selectivity } \\
\text { rate }\end{array}$ & $99 \%$ & $98 \%$ & $90 \%$ & $70 \%$ & $98 \%$ & $93 \%$ & $99 \%$ \\
\hline
\end{tabular}

\section{Conclusion}

Table I. Selectivity rates of different mixtures

The present work demonstrates the feasibility of two cells for a transfer cation based on the electrochemical reversible systems insertion/deinsertion in Chevrel phases. The real operations of the selective transfer are shown with applications for remarkable separations as $\mathrm{Co} / \mathrm{Ni}, \mathrm{Cd} / \mathrm{Ni}$ with $\mathrm{Mo}_{6} \mathrm{~S}_{8}$ and $\mathrm{Zn} / \mathrm{Ni}, \mathrm{Ni} / \mathrm{Cd}, \mathrm{Mn} / \mathrm{Zn}$ with $\mathrm{Mo}_{6} \mathrm{Se}_{8}$.

The extraction of a solution of cation by an electrolytic process could open many ways of application in the mineral liquid waste management. This process is now being developed for investigations of real industrial liquid wastes.

\section{References}

${ }^{[1]}$ R.Chevrel, M.Sergent, J.Prigent, J.Solid State Chem, 3, 515 (1971)

${ }^{[2]}$ R.Schöllorn, R.M.Kümpers, J.O.Besenhard. Mat.Res.Bull, 12, $781-788$ (1977)

${ }^{[3]}$ C.Boulanger, J.M.Lecuire, Electrochemical Acta, 33, 1561-1579 (1988)

${ }^{[4]}$ K.Yvon, Current Topics in Materials Sciences, 3, 53-129 (1979)

${ }^{[5]}$ A.Mançour-Billah and R.Chevrel, Journal of Alloys and Compounds 383, 49-56 (2004)

${ }^{[6]}$ O. Fischer, H. Jones, G. Bongi, M. Sergent et R.Chevrel; Journal of Physic, C, 7 (1974)

${ }^{[7]}$ O. Fischer, H. Treyvaud, G. Bongi, M. Sergent et R.Chevrel; Solid State comm, 17721 (1975)

[8] R.Chevrel, M.Sergent, Superconductivity in ternary Compounds,Topics Curr.phys.,32,Ed.Fischer et M.B.Maple 25, (1982)

${ }^{[9]}$ C.Boulanger- Thèse d'Université, Nancy I (1987)

${ }^{[10]}$ Z.Kaidi- Thèse d'Université, Metz (2000)

${ }^{[11]}$ R.Pantou, M.Guilloux-Viry, L.Burel, J.C.Jegaden, R.Chevrel and A.Perrin J.Solid State Chem, 1, 647-656 (1999)

${ }^{[12]}$ C.Boulanger, J.M.Lecuire, J.Solid State Chem, 25, 45-49 (1987) 